\title{
Aspectos microbiológicos e informação nutricional de molho de tomate orgânico oriundo da agricultura familiar
}

\author{
Microbiological aspects and nutritional information \\ of organic tomato sauce from family farming
}

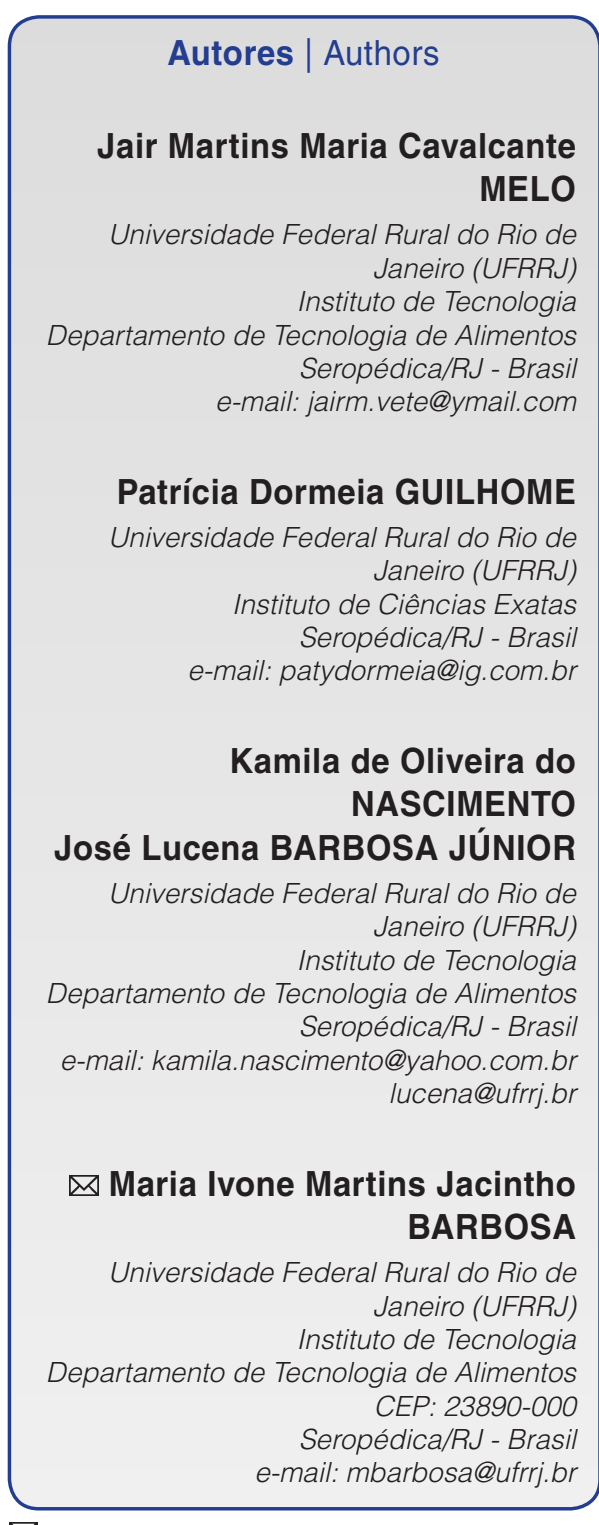

Autor Correspondente / Corresponding Author Publicado / Published: dezembro/2012

\section{Resumo}

O sistema de produção orgânico vem crescendo, tanto em área cultivada como em número de produtores e mercado consumidor. Contudo, informações técnico-científicas sobre estes alimentos in natura e processados ainda são incipientes. O tomate (Lycopersicum esculentum Mill.) desempenha um importante papel para os produtores orgânicos de todo o mundo, em função do retorno financeiro e da grande demanda. O objetivo do presente trabalho foi elaborar um molho de tomate orgânico, aproveitando os saberes dos agricultores, bem como avaliar sua qualidade microbiológica e determinar sua informação nutricional. $O$ molho estudado apresentou $93,45 \%$ de umidade, 0,89\% de proteínas, $0,13 \%$ de lipídeos, $1,50 \%$ de cinzas e $4,03 \%$ de carboidratos totais. Quanto aos aspectos microbiológicos, o molho apresentou condição sanitária satisfatória, de acordo com os padrões estabelecidos pela Agência Nacional de Vigilância Sanitária (ANVISA), e valor calórico menor do que os molhos comerciais disponíveis no mercado. Os produtos processados foram rotulados e vendidos nas feiras agroecológicas da cidade do Rio de Janeiro, agregando valor ao tomate e gerando renda aos agricultores familiares.

Palavras-chave: Tomate; Molho; Alimentos orgânicos; Qualidade; Agricultura familiar.

\section{Summary}

The organic production systems have been raising on cultivated area, producers number and market. However, technical and scientific information about raw and processed material undergoing to organic production system is scarce. Tomato (Lycopersicum esculentum Mill.) plays an important role for organic producers around the world due to its high profits and market acceptance. The aim of this study was to prepare an organic tomato sauce made from the knowledge of familiar farmers and to assess its microbiological quality and nutritional information. The studied product presented $93.45 \%$ of moisture, $0.89 \%$ of protein, $0.13 \%$ of lipids, $1.5 \%$ of ash and $4.03 \%$ of total carbohydrates contents. The products showed a satisfactory sanitary condition according to ANVISA and calorific value lower than the commercial sauces available in the market. The processed products were adequately labeled and sold at the agro-ecological fairs in Rio de Janeiro city, adding value to organic products generating incomes to small farmers.

Key words: Tomato; Sauce; Organic foods; Quality; Small farmers. 


\section{Introdução}

Segundo dados do IBGE (2006), a participação da agricultura familiar em algumas culturas selecionadas representou $87,0 \%$ da produção nacional de mandioca; $70,0 \%$ da produção de feijão (sendo $77,0 \%$ de feijãopreto, $84,0 \%$ de feijão-fradinho, caupi, de corda ou macáçar, e $54,0 \%$ de feijão-de-cor); $46,0 \%$ do milho; $38,0 \%$ do café (parcela constituída por $55,0 \%$ do tipo robusta ou conilon, e 34,0\% do arábica); $34,0 \%$ do arroz, e $58,0 \%$ do leite (composta por $58,0 \%$ do leite de vaca e $67,0 \%$ do leite de cabra). A participação do tipo de produção familiar era, ainda, de $59,0 \%$ do plantel de suínos, $50,0 \%$ do plantel de aves e $30,0 \%$ dos bovinos, e produzia-se $21,0 \%$ do trigo.

Dentro da agricultura familiar, a produção de alimentos orgânicos tem-se mostrado como um diferencial para os pequenos produtores rurais, que já correspodem a aproximadamente 90 mil produtores orgânicos (IBGE, 2010). Esta prática vem ganhando cada vez mais reconhecimento social, político e científico em todo o mundo por estar fundamentada na aplicação de estratégias agroecológicas, mediante o uso de insumos locais, aumentando o valor agregado e propiciando uma cadeia de comercialização mais justa.

O crescimento do mercado de produtos orgânicos tem o seu alicerce na maior conscientização dos consumidores, os quais demandam alimentos saudáveis e seguros quanto à ausência de resíduos químicos e microbiológicos. Além disso, a sociedade vem se preocupando com os danos causados ao ambiente pelo uso abusivo de agrotóxicos na produção de alimentos (MELO et al., 2009).

Dentre as olerícolas orgânicas mais consumidas, destaca-se o tomate (Lycopersicum esculentum Mill.), apesar de apresentar condução relativamente difícil em sistema orgânico. Porém, muitas pesquisas têm sido realizadas e vários resultados têm indicado grandes avanços na condução da cultura, com obtenção de frutos de qualidade, capazes de competir no mercado de hortaliças (BOTREL et al., 2010).

Originário da parte ocidental das Américas Central e do Sul, de onde foi levado para os outros continentes, o tomate continua crescendo em importância no panorama mundial. Apesar de o tomate fazer parte diariamente da alimentação do brasileiro, seja de forma in natura ou industrializada, ainda pouco se conhece sobre a qualidade das diferentes variedades cultivadas, assim como são escassas as referências sobre a qualidade do tomate orgânico (FERREIRA et al., 2010) e, principalmente, de produtos processados.

Segundo Lago et al. (2006), o lançamento de novos produtos, bem como os aspectos de diferenciação de produto; qualidade; nichos de mercado; produtos de origem controlada; agregação de valor; adoção de boas práticas agrícolas; produtos vinculados à imagem de preservação ambiental, e formação de grupos organizados para produzir e comercializar são componentes-chave de uma estratégia voltada à agricultura familiar orgânica. Logo, a elaboração de produtos processados à base de tomate orgânico, como minimamente processado ou molho, é uma estratégia que pode contribuir para agregar valor ao produto, aumentar a competitividade e promover a geração de renda de pequenos produtores.

Assim, o objetivo do presente trabalho foi desenvolver um molho de tomate orgânico, bem como determinar a sua composição centesimal, a qualidade microbiológica e a informação nutricional deste produto, visando a agregar valor ao tomate in natura e promover a geração de renda dos agricultores familiares.

\section{Material e métodos}

As amostras de tomate e das especiarias orgânicas in natura foram colhidas no mês de outubro de 2011 e fornecidas pelos agricultores familiares do SERORGÂNICO de Seropédica-Rio de Janeiro, e o sal foi adquirido no mercado local.

Para a seleção dos ingredientes e a formulação do molho de tomate, foram utilizadas a Resolução RDC n. ${ }^{\circ}$ 276, de 22 de setembro de 2005 - Regulamento técnico para especiarias, temperos e molhos (BRASIL, 2005) - e a Instrução Normativa 18 de 2009 - Regulamento Técnico para Processamento, Armazenamento e Transporte de Produtos Orgânicos (BRASIL, 2009).

Para o processamento do molho de tomate, utilizaram-se, além dos "saberes" dos agricultores, os ingredientes nas proporções descritas na Tabela 1.

Para o processamento do molho, os tomates e as especiarias foram selecionadas visualmente, lavadas e sanitizadas, em solução contendo $0,02 \mathrm{~g} \cdot \mathrm{L}^{-1}$ de cloro ativo por 15 minutos. Em seguida, os tomates foram cortados para a retirada das sementes e todos os ingredientes foram pesados, misturados e submetidos à fervura para concentração. Após atingir a consistência desejada, a concentração final do molho foi determinada utlizando-se um refratrômetro de campo. O molho, na temperatura de

Tabela 1. Proporções e ingredientes utilizados na elaboração do molho de tomate orgânico.

\begin{tabular}{lc}
\multicolumn{1}{c}{ Ingrediente } & $\mathbf{( \% )}$ \\
Tomate $^{*}$ & 94,43 \\
Mistura de especiarias & \\
Cebola & 1,02 \\
Sal & 1,68 \\
Total & 2,88 \\
\hline
\end{tabular}

*Tomate sem sementes; **Especiarias: Alecrim, Manjerona, Orégano, Tomilho e Salsa. 
aproximadamente $80^{\circ} \mathrm{C}$, foi envasado em potes de vidro, previamente lavados e sanitizados, em solução de cloro ativo $\left(0,02 \mathrm{~g} \cdot \mathrm{L}^{-1}\right)$ por 15 minutos, resfriados em banho de gelo até temperatura ambiente e rotulados para a comercialização.

As amostras de molho de tomate destinadas às análises de composição centesimal e microbiológicas foram transportadas à temperatura ambiente até o Laboratório de Análise de Alimentos e Bebidas (LAAB) do Departamento de Tecnologia de Alimentos da Universidade Federal Rural do Rio de Janeiro, onde foram submetidas, simultaneamente, aos ensaios de análise.

Para a determinação da composição centesimal do molho, avaliaram-se os teores de umidade, proteínas, lipídeos e cinzas, segundo as metodologias do Instituto Adolfo Lutz (IAL, 2008). Para a determinação do teor de umidade, pesaram-se $5 \mathrm{~g}$ da amostra em cápsulas de porcelana, que foram submetidas à secagem em estufa a $105{ }^{\circ} \mathrm{C}$ até peso constante; o teor de cinzas totais foi determinado pesando-se 5 gramas da amostra em cadinhos que foram calcinados e incinerados em mufla a $650{ }^{\circ} \mathrm{C}$ por aproximadamente cinco horas, até a obtenção de cinzas claras. Para a determinação do teor de proteínas, quantificou-se o teor de nitrogênio total utilizando-se a técnica de micro-Kjeldahl, enquanto os lipídeos totais foram determinados por extração Soxhlet, utilizando-se como solvente o éter de petróleo. O teor de carboidratos totais (CT) foi calculado por diferença, conforme equação abaixo (BRASIL, 2003a).

$\% \mathrm{CT}=100-(\% \mathrm{U}+\% \mathrm{Cz}+\% \operatorname{Ptns}+\% \mathrm{LT})$

em que:\% Umidade: Umidade; \% Cz: Cinzas totais; \% Ptns: Nitrogênio total; \% LT: Lipídeos totais.

O valor calórico total (VCT) dos frutos estudados foi obtido utilizando-se os fatores de conversões tradicionais de $4 \mathrm{Kcal} / \mathrm{g}$ para carboidrato e proteína, enquanto que, para os lipídeos, foi utilizado de $9 \mathrm{Kcal} / \mathrm{g}$ (BRASIL, 2003).

A informação nutricional do molho de tomate foi determinada de acordo com a RDC N. ${ }^{\circ} 360$ de 2003 - Regulamento Técnico sobre rotulagem nutricional de alimentos embalados (BRASIL, 2003a) -, enquanto que, para o cálculo da porção e da medida caseira, utilizou-se a Resolução RDC n. ${ }^{\circ} 359$ de 2003 - Regulamento Técnico de Porções de Alimentos Embalados para Fins de Rotulagem Nutricional (BRASIL, 2003b).

Para a avaliação da qualidade microbiológica, foi utilizada a Resolução - RDC n. ${ }^{0} 12$, de 2 de janeiro de 2001, que define o Regulamento Técnico para os padrões microbiológicos para alimentos (BRASIL, 2001). Para o grupo de molho de tomate, a Legislação exige que sejam realizadas as análises de Coliformes a 45 ${ }^{\circ} \mathrm{C}$, de Estafilococos coagulase positiva e de Salmonela, segundo as metodologias recomendadas pela American Public Health Association (APHA, 1992).

\section{Resultados e discussão}

A Resolução RDC n. ${ }^{\circ}$ 276/2005 - Regulamento técnico para especiarias, temperos e molhos - define Molhos como produtos em forma líquida, pastosa, emulsão ou suspensão, à base de especiaria(s) e/ou tempero(s) e/ou outro(s) ingrediente(s), fermentados ou não, utilizados para preparar e/ou agregar sabor ou aroma aos alimentos e bebidas (BRASIL, 2005).

Para a formulação do molho de tomate, utilizaram-se apenas ingredientes orgânicos, conforme exigido pela IN 18/2009, com exceção do sal. Cabe destacar que o emprego de sal $(\mathrm{NaCl})$ é permitido sem restrições e o mesmo não deve ser incluído no cálculo do percentual de ingredientes orgânicos (BRASIL, 2009). Logo, pode-se afirmar que o molho de tomate foi formulado com 100\% de ingredientes orgânicos.

O molho estudado apresentou 93,45 \pm 0,42\% de umidade, $0,89 \pm 0,04 \%$ de proteínas, $0,13 \pm 0,02 \%$ de lipídeos, $1,50 \pm 0,24 \%$ de cinzas e 4,03 $\pm 0,1 \%$ de carboidratos totais. Estes resultados diferiram dos reportados para molhos de tomate industrializados disponíveis na Tabela TACO (UNICAMP, 2011), que apresentaram $88,1 \%$ de umidade, 1,4\% de proteínas, 0,9\% de lipídeos, 7,7\% de carboidratos, 3,1\% de fibras e 1,9\% de cinzas. Esta diferença pode ser justificada em função da composição química dos molhos, que pode variar de acordo com a cultivar do tomate, o tipo e as proporções dos ingredientes utilizados na formulação.

No Quadro 1, está apresentada a declaração simplificada da informação nutricional do molho de tomate no modelo vertical $A$, segundo recomendado pela RDC 360/2003 (BRASIL, 2003a).

A RDC 360/2003 é o Regulamento Técnico que define a Rotulagem Nutricional como toda descrição destinada a informar ao consumidor sobre as propriedades nutricionais de um alimento. A rotulagem nutricional compreende a declaração do valor energético dos nutrientes e das propriedades nutricionais (informação nutricional complementar).

De acordo com a RDC 360 de 2003, é obrigatório declarar na informação nutricional o valor energético e

Quadro 1. Informação nutricional do molho de tomate orgânico.

\begin{tabular}{|c|c|c|}
\hline \multicolumn{3}{|c|}{$\begin{array}{l}\text { Informação nutricional } \\
\text { Porção } 60 \mathrm{~g} \text { (3 colheres de sopa) }\end{array}$} \\
\hline & Quantidade por porção & VD $(\%)^{*}$ \\
\hline Valor energético & $8,4 \mathrm{Kcal}=39,6 \mathrm{KJ}$ & 0,42 \\
\hline Carboidratos & $1,6 \mathrm{~g}$ & 2,1 \\
\hline Proteínas & $0,5 \mathrm{~g}$ & 2,4 \\
\hline
\end{tabular}

Não contém quantidades significativas de proteínas, gorduras totais, gorduras saturadas, gorduras trans, fibra alimentar e sódio. * \% Valores Diários de referência com base em uma dieta de $2.000 \mathrm{Kcal}$ ou $8.400 \mathrm{KJ}$. Seus valores diários podem ser maiores ou menores, dependendo de suas necessidades energéticas. 
Aspectos microbiológicos e informação nutricional de molho de tomate orgânico oriundo da agricultura familiar

MELO, J. M. M. C. et al.

os seguintes nutrientes: carboidratos, proteínas, gorduras (saturadas, insaturadas e trans), fibra alimentar e sódio, desde que estes teores sejam significativos para a porção. Adicionalmente, as vitaminas e os minerais podem ser declarados de forma opcional quando estiverem presentes em quantidade igual ou maior a 5\% da Ingestão Diária Recomendada (IDR), por porção indicada no rótulo.

A RDC 359/2003 é a legislação que regulamenta as porções de alimentos embalados para Fins de Rotulagem Nutricional. Esta Resolução define porção e medida caseira, como:

- Porção: é a quantidade média do alimento que deveria ser consumida por pessoas sadias, maiores de 36 meses de idade em cada ocasião de consumo, com a finalidade de promover uma alimentação saudável; e

- Medida caseira: é um utensílio comumente utilizado pelo consumidor para medir alimentos.

Para a elaboração da informação nutricional do molho de tomate, foram considerados apenas os teores de carboidratos $(1,6 \mathrm{~g})$ e de proteínas $(0,5 \mathrm{~g})$, pois foram os únicos significativos para a porção de $60 \mathrm{~g}$, recomendada para a categoria "molhos" (BRASIL, 2003b). A medida caseira, para esta categoria, correspondeu a três colheres de sopa, conforme a RDC 359/2003 (BRASIL, 2003b) (Quadro 1).

O valor calórico do molho foi de 8,4 Kcal e apenas os carboidratos e as proteínas apresentaram teores significativos para a porção (Quadro 1). Os teores de gorduras totais, gorduras saturadas, gorduras trans, fibra alimentar e sódio para a porção de $60 \mathrm{~g}$ de molho ficaram abaixo dos limites significativos, sendo declarados na informação nutricional como não significativos (Quadro 1).

Comparando-se o valor calórico do molho estudado com o de duas marcas líderes disponíveis no mercado, observou-se que o molho do presente estudo foi, aproximadamente, três vezes menos calórico que os molhos da marca A (25 Kcal) e da marca B (22 Kcal). Esta diferença pode ser justificada pela diferença de formulação dos molhos e, principalmente, porque, nas marcas comerciais, há adição de amido modificado, o que pode ter contribuído para o aumento do valor calórico.

Nas análises microbiológicas realizadas no molho de tomate, foi encontrada contagem de: Coliformes termotolerantes $(\mathrm{NMP} / \mathrm{g})<3,0$ est; Estafilococos coagulase $(\mathrm{UFC} / \mathrm{g})<1,0 \times 10^{2}$ est, e ausência de Salmonela em $25 \mathrm{~g}$. Estes resultados sugerem que as amostras estavam dentro dos padrões microbiológicos de qualidade exigidos pela Agência Nacional de Vigilância Sanitária (ANVISA) e que as normas de Boas Práticas de Fabricação (BPF) foram seguidas pelos agricultores de forma satisfatória.

\section{Conclusão}

- O molho estudado apresentou condição sanitária satisfatória, atendendo aos padrões sanitários estabelecidos pela Legislação vigente;

- O valor calórico do molho de tomate foi menor do que os de marcas comerciais disponíveis no mercado; e

- O produto foi rotulado e vendido nas feiras agroecológicas da cidade do Rio de Janeiro, agregando valor ao tomate e gerando renda para esses agricultores familiares.

\section{Agradecimentos}

Os autores agradecem ao apoio financeiro do Banco Santander/Unisol e do PROEXT/MEC 2011-2012. À Capes, pelo Pró-equipamento Capes/2010 e pela Bolsa de Doutorado da terceira autora.

\section{Referências}

AMERICAN PUBLIC HEALTH ASSOCIATION - APHA. Technical committee on microbiological methods for food. In: VANDERZANT, C.; SPLITTSTOESSER, D. F. Compendium of Methods for the Microbiological Examination of Foods. 3rd ed. Washington: APHA, 1992. p. 336-383.

BRASIL. Ministério da Saúde. Agência Nacional de Vigilânncia Sanitária - ANVISA. Resolução RDC n 12, de 02 de janeiro de 2001. Regulamento técnico sobre padrões microbiológicos em alimentos. Diário Oficial da República Federativa do Brasil, Poder Executivo, Brasília, DF, 10 jan. 2001. Seção 1. Disponível em: <www.anvisa.gov.br/legis/resol/12_01rdc.htm>. Acesso em: 05 de julho de 2012

BRASIL. Ministério da Saúde. Agência Nacional de Vigilânncia Sanitária - ANVISA. Resolução RDC n³60, de 23 de dezembro de 2003. Regulamento técnico sobre rotulagem nutricional de alimentos embalados. Diário Oficial da República Federativa do Brasil, Poder Executivo, Brasília, DF, 26 dez. 2003a. Seção 1, n. 251, p. 33. Disponível em: <http://www.anvisa.gov.br/legis/>. Acessado: 05 de julho de 2012.

BRASIL. Ministério da Saúde. Agência Nacional de Vigilânncia Sanitária - ANVISA. Resolução RDC n 359, de 23 de dezembro de 2003. Regulamento técnico de porções de alimentos embalados para fins de rotulagem nutricional. Diário Oficial da República Federativa do Brasil, Poder Executivo, Brasília, DF, 26 dez. 2003b. Seção 1, n. 251, p. 28. Disponível em: <http:// www.anvisa.gov.br/legis/>. Acessado: 05 de julho de 2012.

BRASIL. Ministério da Saúde. Agência Nacional de Vigilância Sanitária - ANVISA. Resolução RDC n² 276, de 22 de setembro de 2005. Aprova o Regulamento Técnico para Especiarias, Temperos e Molhos. Diário Oficial da República Federativa do 
Aspectos microbiológicos e informação nutricional de molho de tomate orgânico oriundo da agricultura familiar MELO, J. M. M. C. et al.

Brasil, Poder Executivo, Brasília, DF, 23 set. 2005. Disponível em: <http://www.anvisa.gov.br/legis/>. Acesso em: 20 jan. 2012.

BRASIL. Ministério da Agricultura, Pecuária e Abastecimento - MAPA. Instrução Normativa Conjunta $n^{\circ} 18$, de 28 de maio de 2009. Aprova o Regulamento técnico para o processamento, armazenamento e transporte de produtos orgânicos. Diário Oficial da República Federativa do Brasil, Poder Executivo, Brasília, DF, 29 maio 2009. Seção 1, p. 15.

BROTEL, N.; RESENDE, F. V.; NASSUR, R. C. M.; BOAS, E. V. B. V. Qualidade de Tomates Cultivados em Sistema Orgânico e Armazenados em Temperatura Ambiente e Refrigerada. Brasília: Embrapa Hortaliças, 2010. 24 p. (Boletim de Pesquisa e Desenvolvimento, n. 72).

INSTITUTO ADOLFO LUTZ - IAL. Métodos Físico-Químicos para Análise de Alimentos. São Paulo: IAL, 2008. 1020 p. Disponível em: <http://www.ial.sp.gov.br/>. Acesso em: 07 jul. 2011.

INSTITUTO BRASILEIRO DE GEOGRÁFIA E ESTÁTISTICA - IBGE. Censo Agropecuário. Rio de Janeiro: IBGE, 2006.

INSTITUTO BRASILEIRO DE GEOGRÁFIA E ESTÁTISTICA - IBGE. Produção Agrícola Municipal. Rio de Janeiro: IBGE, 2010. v. 37.
FERREIRA, S. M. R.; FREITAS, R. J. S.; KARKLE, E. N. L.; QUADROS, D. A., TULLIO, L. T.; LIMA, J. J. Qualidade do tomate de mesa cultivado nos sistemas convencional e orgânico. Ciência e Tecnologia de Alimentos, Campinas, v. 30, n. 1, p. 224-230, jan./mar. 2010. http://dx.doi.org/10.1590/S010120612010000100033

MELO, P. C. T.; TAMISO, L. G.; AMBROSANO, E. J.; SCHAMMASS, E. A.; INOMOTO, M. M.; SASAKI, M. E. M.; ROSSI, F. Desempenho de cultivares de tomateiro em sistema orgânico sob cultivo protegido. Horticultura Brasileira, Brasília, v. 27, n. 4, p. 553-559, out./dez. 2009. Disponível em: <http://www. scielo.br/scielo.php?script=sci_arttext\&pid=\$010205362009 000400025\&lang=pt> Acesso em: 19 jul. 2010. http://dx.doi. org/10.1590/S0102-05362009000400025

LAGO, A.; LENGLER, L.; CORONEL, D. A.; SILVA, T. N. Agricultura Familiar de Produtos Orgânicos: Um Olhar Sob a Ótica do Marketing. Revista Extensão Rural, Santa Maria, v. 13, n. 3, p. 94-116, 2006.

UNIVERSIDADE ESTADUAL DE CAMPINAS - UNICAMP. Tabela Brasileira de Composição de Alimentos - TACO. 4. ed. rev. e ampl. Campinas: UNICAMP/NEPA, 2011. 116 p. Disponível em: <http://www.unicamp.br/nepa/taco/contar/taco_versao4.pdf>. Acesso em: 05 jul. 2012. 